\title{
Effects of Coronary ARTery Disease in Patients Undergoing TRANSCATHETER AORTIC VALVE IMPLANTATION: \\ A Study Of Age- AND Gender-Matched COHORTS
}

\author{
Anna Franzone $\mathrm{MD}^{* 1}$, Stefan Stortecky MD*1, Lorenz Räber MD PhD ${ }^{1}$, \\ Dik Heg PhD², Kyohei Yamaji MD², Raffaele Piccolo MD¹, Masahiko Asami MD¹, \\ Jonas Lanz $\mathrm{MD}^{1}$, Fabien Praz $\mathrm{MD}^{1}$, Kostantinos Koskinas $\mathrm{MD}^{1}$, Thomas Zanchin $\mathrm{MD}^{1}$, Peter \\ Wenaweser $\mathrm{MD}^{1}$, Marco Valgimigli MD PhD${ }^{1}$, Peter Jüni $\mathrm{MD}^{3}$, Thomas Pilgrim $\mathrm{MD}^{1}$, and
} Stephan Windecker $\mathrm{MD}^{1}$

*Drs. Franzone and Stortecky contributed equally to this work.

Word count: 2,561

\begin{abstract}
${ }^{1}$ Department of Cardiology, Swiss Cardiovascular Center, University Hospital, Bern. This author takes responsibility for all aspects of the reliability and freedom from bias of the data presented and their discussed interpretation.

${ }^{2}$ Institute of Social and Preventive Medicine and Clinical Trials Unit, Bern University Hospital, Bern, Switzerland. This author takes responsibility for all aspects of the reliability and freedom from bias of the data presented and their discussed interpretation.

${ }^{3}$ Applied Health Research Centre (AHRC), Li Ka Shing Knowledge Institute of St. Michael's Hospital, and Department of Medicine, University of Toronto, Canada. This author takes responsibility for all aspects of the reliability and freedom from bias of the data presented and their discussed interpretation.
\end{abstract}

Address for correspondence:
Stephan Windecker, MD

Professor and Chairman of Cardiology

Department of Cardiology

Bern University Hospital

University of Bern

3010 Bern

Switzerland

email: stephan.windecker@insel.ch 


\section{Conflict of Interests}

Prof Windecker reports having received research grants to the institution from Abbott, Biotronik, Boston Scientific, Edwards Lifesciences, Medtronic, Medicines Company, and St Jude as well as speaker fees from AstraZeneca, Eli Lilly, Abbott, Biotronik, Boston Scientific, Bayer, and Biosensors.

Prof Wenaweser has received honoraria and lecture fees from Medtronic and Edwards Lifesciences and has received an unrestricted grant from Medtronic to the institution (University of Bern).

Prof Jüni is an unpaid steering committee or statistical executive committee member of trials funded by Abbott Vascular, Biosensors, Medtronic, and Johnson \& Johnson. All other authors have no relationships relevant to the contents of this article to disclose. 


\begin{abstract}
Background: The prognostic role of concomitant coronary artery disease (CAD) among patients undergoing transcatheter aortic valve implantation (TAVI) is still uncertain.
\end{abstract}

Methods: Data from the Bern TAVI Registry and the Bern PCI Registry were analyzed. Patients with concomitant CAD undergoing TAVI (TAVI+CAD) were age- and gender-matched to the following two cohorts: patients without CAD undergoing TAVI (TAVI-noCAD) and patients with stable CAD undergoing percutaneous coronary intervention (CAD-noAS). Major adverse cardiovascular and cerebrovascular events (MACCE), defined as the composite of cardiovascular death, myocardial infarction, or cerebrovascular events, represented the primary endpoint at 1-year.

Results: Out of 9,478 procedures performed between 2007 and 2013 (807 TAVI; 8,671 PCI), three cohorts, each including 248 subjects, were derived. At 1-year, MACCE were significantly increased among TAVI+CAD compared with TAVI-noCAD (16.8\% vs. 9.8\%, hazard ratio, $\mathrm{HR}, 1.75,95 \%$ confidence intervals, $\mathrm{Cl}, 1.06-2.89, \mathrm{p}=0.030$ ) and $\mathrm{CAD}-\mathrm{noAS}$ patients (16.8\% vs. 9.5\%, HR 1.85, 95\% CI 1.11-3.09, $\mathrm{p}=0.018$ ) whereas no difference was found between TAVI-noCAD and CAD-noAS patients. The higher rate of MACCE among TAVI+CAD patients was mainly driven by an increased risk of cardiovascular mortality compared with the TAVI-noCAD (HR 1.86, 95\%Cl 1.03-3.36, $\mathrm{p}=0.040$ ) and CAD-noAS cohorts (HR 2.29, 95\%Cl 1.22-4.30, $\mathrm{p}=0.010)$. The 1-year rate of MACCE was similar between TAVI-noCAD and CADnoAS patients (9.8\% vs. 9.5\%, HR 1.05, 95\%Cl 0.59-1.87, $\mathrm{p}=0.86)$.

Conclusions: Concomitant CAD in the setting of TAVI conveyed an increased risk of ischemic events and cardiovascular mortality at 1-year follow-up.

Key words: coronary artery disease, transcatheter aortic valve implantation, prognosis, mortality 


\section{Introduction}

Aortic stenosis (AS) and coronary artery disease (CAD) frequently coexist owing to several common pathobiological factors.[1 2] Obstructive CAD has been associated with impaired clinical outcomes among patients undergoing surgical aortic valve replacement.[3 4] Yet, its prognostic role in the setting of transcatheter aortic valve implantation (TAVI) remains controversial.[5-7] Indeed, while some studies showed an increased risk of mortality and cardiovascular events after TAVI in the presence of concomitant CAD, [8-10] other studies provided neutral findings.[11-14] A lack of uniformity in the definition of CAD and a limited power are important limitations inherent to these studies.[15 16] In this context, the evaluation of the prognostic effect of concomitant CAD is also challenged by the risk profile of TAVI patients. Advanced age is likely to be a significant confounding factor with the potential to camouflage or rather heighten the risk of CAD-related outcomes after TAVI. Furthermore, the need for myocardial revascularization was a key exclusion criterion among pivotal trials that have established the role of TAVI in the management of severe AS.[15 16] Therefore, the aim of the present study was to define the prognostic role of CAD among TAVI patients by comparing the 1-year clinical outcomes of patients with concomitant CAD undergoing TAVI with age- and gender- matched cohorts of TAVI patients without CAD and patients with stable CAD in absence of AS who underwent percutaneous coronary intervention $(\mathrm{PCI})$. 


\section{Methods}

\section{Patient population and study cohort definitions}

The present study presents a three-arm, age- and gender-matched cohort design. All patients undergoing TAVI were included in the Bern TAVI registry (which is part of the Swiss TAVI Registry, NCT01368250) and all patients undergoing PCl were included in the Bern PCI registry (NCT02241291). All TAVI patients were evaluated for the presence of significant CAD, defined as history of surgical and/or percutaneous coronary revascularization, previous myocardial infarction (MI) and/or at least one significant lesion (diameter stenosis $\geq 50 \%$ ) at the site of a major native coronary vessel or bypass graft by visual assessment in the coronary angiography performed within four weeks prior to TAVI. From the Bern PCI registry, only patients with stable CAD were deemed eligible for matching. The study complied with the declaration of Helsinki. Both registries were approved by the local ethics committee and all patients gave written informed consent to participate.

\section{Procedures}

The eligibility for TAVI was discussed within the local Heart Team and based on an extensive clinical and anatomical pre-operative assessment. Patients eligible for TAVI with concomitant $\mathrm{CAD}$ received $\mathrm{PCI}$ prior TAVI or during the same procedure on the basis of a consensus decision taking into account the myocardium at risk, the lesion complexity and symptom status. At this regard, internal guidelines, recommending preventive revascularization of significant proximal stenosis of major coronary arteries were followed. Functional ischemia testing was not routinely performed in view of the low diagnostic yield of stress testing in patients with aortic stenosis. 
Patients in the TAVI cohort received either the Medtronic CoreValve bioprosthesis (Medtronic, Minneapolis, MN, USA), the Edwards Sapien transcatheter heart valve (Edwards LifeSciences, Irvine, CA, USA), or the Symetis Acurate TA aortic bioprosthesis (Symetis, Ecublens, Switzerland) through the femoral, transapical, or subclavian access, as previously described.[17]

Current practice guidelines were followed in all patients in case of PCI.[18] Unfractionated heparin at a dose of at least $5,000 \mathrm{IU}$ or $70-100 \mathrm{IU} / \mathrm{kg}$ was administered during the procedure. Management of antithrombotic medication consisted of dual antiplatelet therapy (DAPT) with acetylsalicylic acid and clopidogrel initiated before, at the time, or immediately after the procedure and recommended typically for 6 months after TAVI and for 12 months after $\mathrm{PCl}$ (with or without TAVI). Acetylsalicylic acid was continued indefinitely after single or combined procedures.

\section{Clinical follow-up}

Patients included in the Bern TAVI registry were prospectively evaluated for the occurrence of adverse cardiac and cerebrovascular events in-hospital, at discharge and were contacted after 30 days and 12 months by means of clinic visit or standardized telephone interview. Patients in the Bern $\mathrm{PCl}$ registry were prospectively followed after the index $\mathrm{PCl}$ and were contacted after hospital discharge, during any unscheduled hospital visit or planned hospital visits (eg. staged procedures), and at 1 year after the index procedure.

\section{Study endpoints and definitions}

The primary study endpoint was a composite of major adverse cardiovascular and cerebrovascular events (MACCE), including cardiovascular death, myocardial infarction (MI), 
or cerebrovascular events, at 1 year. Secondary endpoints were the individual components of the primary endpoint as well as all-cause mortality.

Events occurring in patients undergoing TAVI were adjudicated by a clinical event committee consisting of interventional cardiologists and cardiac surgeons, according to the updated recommendations of the Valve Academic Research Consortium (VARC-2).

For patients in the Bern PCl Registry, a clinical event committee adjudicated all adverse events. Cardiac death was defined as any death due to an immediate cardiac cause, procedure-related mortality, and death of unknown cause; MI was defined as periprocedural $(<48 \mathrm{~h}$ after $\mathrm{PCl})$ in presence of electrocardiographic signs of ischemia and elevation of biomarkers of cardiac damage (increase in CK to more than twice the normal value with increased values of CK-MB fraction or troponin higher than usual) or spontaneous (>48h after $\mathrm{PCl}$ ) if recurrent thoracic chest pain or ischemic equivalent symptoms occurred together with new ischemic electrocardiographic signs and biomarker elevation with rise and/or fall of cardiac biomarkers with at least one value above the 99th percentile upper reference limit. Stroke was defined as rapid development of clinical signs of focal or global disturbance of cerebral function lasting $>24$ hours with imaging evidence of acute, clinically relevant brain lesion.

\section{Statistical analysis}

Triple matching (1:1:1) of patients with TAVI and concomitant CAD (TAVI+CAD) vs. TAVI without CAD (TAVI-noCAD) vs. patients with stable CAD undergoing PCI (CAD-noAS) was performed. Triplets were matched according to gender and age (using a caliper of 0.02), randomly selected from a cohort of 795 TAVI patients from the Bern TAVI Registry and 3,528 patients with stable CAD from the Bern PCI Registry (see Figure 1 for patient flow). Discrete 
data were summarized as numbers and frequencies (\%) whereas continuous data were presented as means \pm standard deviations (SD). $P$-values for characteristics recorded at the patient level were calculated with un-paired t-tests, chi-square tests, or Fisher's exact tests, except when specified. Statistical significance was considered at $p<0.05$.

Clinical outcomes at 30 days and 1 year were expressed as counts and incidence rates computed according to the Kaplan-Meier method (censored at 30 days or 1 year, respectively). Hazard ratios were computed using Cox's regressions for death, cardiovascular death, CVE, MI, and the composites of these endpoints. A landmark analysis at 30 days was performed to evaluate clinical events through the different study cohorts during the early (0-30 days) and late (31-365 days) follow-up period. Statistical analyses were performed using Stata 13.1 (College Station, TX: StataCorp LP).

\section{Results}

Out of 9,478 procedures performed between 2007 and 2013 (807 TAVI; 8,671 PCI), three cohorts were derived as follows (Supplemental Figure 1): among 795 patients included in the Bern TAVI registry, CAD at baseline was identified in 514 (65\%) patients (TAVI+CAD), leaving 281 (35\%) patients without CAD (TAVI-noCAD). A total of 3,528 patients with stable CAD and without AS (CAD-noAS) underwent PCl and were included in the Bern PCI registry. After matching for age and gender (TAVI+CAD : TAVI-noCAD : CAD-noAS, $1: 1: 1$ ), three cohorts including 248 patients each (62\% male) were obtained. 


\section{Baseline characteristics}

Table 1 shows baseline clinical characteristics of the three study cohorts (baseline features of the population prior to matching are detailed in Supplemental Table 1). TAVI+CAD and CAD-noAS patients had a similar risk profile, except for diabetes mellitus (33.5\% vs. $18.5 \%$, $p<0.001)$, chronic renal failure $(76.1 \%$ vs. $63.0 \%, p=0.002)$, and peripheral artery disease (19.8\% vs. $11.3 \%, p=0.01)$ occurring at higher rate in the TAVI+CAD cohort.

Hypercholesterolemia and arterial hypertension were more common among patients with CAD (TAVI+CAD and CAD-noAS) as compared with the TAVI-noCAD cohort. Regarding medication at discharge, CAD-noAS patients were more likely to receive DAPT, whereas TAVI patients more frequently had oral anticoagulants related to a higher prevalence of atrial fibrillation.

Procedural details among patients undergoing TAVI with or without CAD are summarized in Supplemental Table 2.

\section{Clinical events throughout 1-year follow-up}

Rates of clinical outcomes across the study cohorts are reported in Table 2. At 30-day followup, there was no significant difference for the primary endpoint of MACCE between the TAVI+CAD and TAVI-noCAD (7.3\% vs. 5.6\%, HR 1.30, 95\% Cl 0.64-2.61, $p=0.47)$. Similarly, the risk of MACCE was not significantly different between the TAVI+CAD and the CAD-noAS groups (7.3\% vs. 3.6\%, HR 2.02, 95\% Cl 0.91-4.50, $p=0.085)$. Cerebrovascular events occurred more frequently among TAVI patients, irrespective of CAD status (TAVI+CAD: 3.2\%; TAVInoCAD: $4.4 \%$, CAD-noAS: $0 \% ; p=0.007$ for both TAVI+CAD and TAVI-noCAD vs. CAD-noAS). At 1-year follow-up, MACCE were significantly increased among TAVI+CAD patients compared with TAVI-noCAD (16.8\% vs. 9.8\%, HR 1.75, 95\% Cl 1.06-2.89, $p=0.030)$ and CAD- 
noAS patients (16.8\% vs. 9.5\%, HR 1.85, 95\% Cl 1.11-3.09, $p=0.018)$ (Figure 1). This difference was mainly driven by a higher rate of cardiovascular mortality in the TAVI+CAD cohort relative to the TAVI-noCAD (12.7\% vs. $7.0 \%, \mathrm{HR} 1.86,95 \% \mathrm{Cl} 1.03-3.36, p=0.040)$ and CAD-noAS groups (12.7\% vs. 5.8\%, HR 2.29, 95\% Cl 1.22-4.30, p=0.010). In TAVI patients without $C A D$, the rate of MACCE was similar to CAD patients undergoing $\mathrm{PCl}$ (9.8\% vs. 9.5\%, HR 1.05, 95\% Cl 0.59-1.87, $p=0.86)$.

The landmark analysis at 30-day follow-up showed that during the peri-procedural period, the MACCE rate was consistently higher among patients undergoing TAVI (irrespective of CAD) when compared with the CAD-noAS patient population. However, beyond 30 days, event curves were similar for TAVI-noCAD and CAD-noAS patients, whereas continuously diverging event curves were observed for TAVI+CAD patients throughout the first year (Figure 2).

\section{Clinical impact of PCl among patients undergoing TAVI}

A total of 110 patients $(44.4 \%, 148$ lesions) in the TAVI+CAD cohort underwent PCI prior or in the context of TAVI. Of these, more than half (54.3\%) presented with significant lesions involving the proximal segments of the major epicardial coronary arteries $(20.2 \%$ left anterior descending artery, $8.7 \%$ circumflex artery, 9.4\% right coronary artery). 8 patients (7.3\%) underwent $\mathrm{PCl}$ of the left main coronary artery and 12 (10.9\%) patients had $\mathrm{PCl}$ of bypass grafts. Supplemental Table 3 provides angiographic and procedural characteristics of TAVI+CAD and CAD-noAS patients. Compared with CAD-no AS, TAVI+CAD patients presented with significantly higher baseline and residual Syntax Score. As shown in Supplemental Table 4, within the TAVI+CAD group, $\mathrm{PCl}$ was not associated with a significant difference in 
MACCE during early (6.8\% vs. $7.8 \%, \mathrm{PCl}$ vs. no $\mathrm{PCl}, p=0.75)$ and overall follow-up $(14.9 \%$ vs. $18.2 \%, \mathrm{PCl}$ vs no $\mathrm{PCl}, p=0.49)$.

\section{Discussion}

The salient findings of the present study investigating the prognostic role of CAD among patients undergoing TAVI are as follows:

1. Patients with AS and concomitant CAD undergoing TAVI were at higher risk for MACCE and cardiovascular mortality compared with age-and gender-matched TAVI patients without $C A D$ and patients with stable $C A D$ undergoing $\mathrm{PCl}$.

2. In the absence of significant CAD, TAVI patients had a risk of ischemic adverse events that approached age- and gender-matched patients with stable CAD undergoing PCl. Although CAD is found in more than two thirds of patients considered for TAVI,[2] its prognostic role in this setting remains controversial. The presence of CAD, as defined by a history of percutaneous or surgical myocardial revascularization, has been reported to be associated with $>10$-fold higher risk of 30-day mortality.[12 16] If a history of previous MI and angiographic evidence of significant $(>50 \%)$ coronary artery stenosis was considered to define relevant $C A D$, comparable survival rates were reported throughout 1-year followup.[11] Moreover, at long-term follow-up, CAD was an independent predictor of mortality among patients included in the UK-TAVI Registry.[19]

However, two aspects should be factored when evaluating the association of concomitant degenerative AS and CAD. First, both conditions are closely associated with ageing, which in turn predicts mortality.[20 21] Second, gender has an independent prognostic role among patients undergoing TAVI [22-25] and a significant treatment interaction between TAVI and 
surgery has been reported in randomized trials.[16 26] In view of these considerations, the comparison across the three cohorts matched for age and gender was meant to account for these relevant factors. Indeed, a significantly increased risk of ischemic events emerged among TAVI patients with concomitant CAD relative to their counterpart without CAD, and this risk was also higher compared with patients with stable CAD undergoing PCl.

There are several pathophysiological mechanisms which may explain the adverse association between CAD and severe AS. Arguably, the presence of ischemic myocardium, notwithstanding a successful relief of the valvular stenosis, may circumvent reverse left ventricular remodeling and the improvement of systolic and diastolic function.[27 28] Such mechanisms could play a role particularly in patients with a history of previous MI. On the other hand, excessive myocardial hypertrophy, which typically develops in response to sustained pressure overload by a narrowed aortic valve, may precipitate the ischemic burden associated with a significant, flow-limiting, coronary stenosis. Consistently, in the current study, the higher risk of MACCE observed among patients with concomitant CAD undergoing TAVI was mainly related to a heightened risk of cardiovascular mortality.

The comparison of TAVI patients with concomitant CAD against those with stable CAD in the absence of AS may inform more comprehensively on the natural history of CAD and AS. In the TAVI+CAD cohort, a greater number of patients presented with diabetes mellitus, peripheral artery disease or chronic renal failure compared with subjects with stable CAD in absence of AS. Thus, patients with both CAD and severe AS may harbor a more extensive burden of atherosclerotic disease. Furthermore, TAVI+CAD patients presented with a significantly higher Syntax score at baseline, suggesting a greater extent and complexity of CAD than CAD-no AS patients that was not offset by PCI. Residual Syntax score, indeed, remained higher in TAVI+CAD relative to their counterpart without valve disease. An indirect 
proof of the negative impact of significant CAD is that clinical outcomes of TAVI patients without $C A D$ were similar to those of patients with stable $C A D$ undergoing $P C l$, particularly outside the peri-procedual period. Therefore, the prognosis of TAVI patients, when compared against a reference group of stable CAD patients undergoing $\mathrm{PCl}$, seemed to be largely dominated by the presence of additional CAD rather than other factors.

Overall, in our cohort, $40 \%$ of TAVI patients with CAD underwent $\mathrm{PCl}$, a proportion somewhat higher compared with other reports. Nevertheless, this resulted from a standardized internal protocol that consists of performing coronary revascularization on the basis of the Heart Team decision and taking into account the overall risk profile of the patients, the clinical presentation and the severity of CAD as assessed by visual estimation. TAVI and $\mathrm{PCl}$ of angiographically significant $(\geq 50 \%$ ) stenoses in major epicardial vessels are frequently performed in the same session. However, a staged procedure strategy (some days prior to TAVI or alternatively in the early post-procedural phase) is adopted to minimize contrast load in patients at higher risk for acute kidney injury. Of note, we found that concomitant $\mathrm{PCl}$ did not result in a lower rate of clinical events after TAVI. This observation should not imply that $\mathrm{PCl}$ is dispensable in TAVI candidates, rather indicates that the adverse prognosis featuring the TAVI+CAD group was still noticeable on top of contemporary treatment. In this respect, several randomized trials designed to investigate revascularization modalities and the optimal timing of intervention in patients undergoing TAVI are ongoing (ISRCTN75836930, NCT01586910, NCT02797158). As such, the present study highlights the magnitude of risk conferred by CAD among TAVI patients demanding a major research effort to mitigate the influence of CAD in this setting. 


\section{Limitations}

The results of this study should be interpreted in the context of the following limitations. First, the study population was based on the experience of a single center. Secondly, the presence of myocardial ischemia was not routinely collected and therefore it was not considered in the definition of CAD among TAVI patients. Thirdly, the study cohorts were matched on the basis of age and gender. Therefore, a possible imbalance due to residual confounders factors cannot be excluded. Fourth, the analysis included elderly subjects, considered to be at increased risk for surgical aortic valve replacement. As a consequence, the present findings could not be extended to lower risk categories of TAVI.

\section{Conclusions}

In an age- and gender- matched cohort study, the presence of CAD among TAVI patients conferred an adverse prognosis in terms of major adverse events and cardiovascular mortality. In the absence of CAD, TAVI patients incurred in a rate of ischemic events that was similar to patients with stable CAD undergoing PCl during 1-year follow-up. 


\section{References}

1. Carabello BA, Paulus WJ. Aortic stenosis. Lancet 2009;373(9667):956-66 doi: 10.1016/S0140-6736(09)60211-7[published Online First: Epub Date]|.

2. Stefanini GG, Stortecky S, Meier B, Windecker S, Wenaweser P. Severe aortic stenosis and coronary artery disease. Eurolntervention 2013;9 Suppl:S63-8 doi: 10.4244/EIJV9SSA12[published Online First: Epub Date]|.

3. Beach JM, Mihaljevic T, Svensson LG, et al. Coronary artery disease and outcomes of aortic valve replacement for severe aortic stenosis. J Am Coll Cardiol 2013;61(8):837-48 doi: 10.1016/j.jacc.2012.10.049[published Online First: Epub Date]|.

4. Tjang YS, van Hees Y, Korfer R, Grobbee DE, van der Heijden GJ. Predictors of mortality after aortic valve replacement. Eur J Cardiothorac Surg 2007;32(3):469-74 doi: 10.1016/j.ejcts.2007.06.012[published Online First: Epub Date]|.

5. Nkomo VT, Gardin JM, Skelton TN, Gottdiener JS, Scott CG, Enriquez-Sarano M. Burden of valvular heart diseases: a population-based study. Lancet 2006;368(9540):1005-11 doi: 10.1016/S0140-6736(06)69208-8[published Online First: Epub Date]|.

6. Joint Task Force on the Management of Valvular Heart Disease of the European Society of C, European Association for Cardio-Thoracic S, Vahanian A, et al. Guidelines on the management of valvular heart disease (version 2012). Eur Heart J 2012;33(19):245196 doi: 10.1093/eurheartj/ehs109[published Online First: Epub Date]|.

7. Piccolo R, Giustino G, Mehran R, Windecker S. Stable coronary artery disease: revascularisation and invasive strategies. Lancet 2015;386(9994):702-13 doi: 10.1016/S0140-6736(15)61220-X[published Online First: Epub Date]|.

8. Stefanini GG, Stortecky S, Cao D, et al. Coronary artery disease severity and aortic stenosis: clinical outcomes according to SYNTAX score in patients undergoing transcatheter aortic valve implantation. Eur Heart J 2014;35(37):2530-40 doi: 10.1093/eurheartj/ehu074[published Online First: Epub Date]|.

9. Dewey TM, Brown DL, Herbert MA, et al. Effect of concomitant coronary artery disease on procedural and late outcomes of transcatheter aortic valve implantation. Ann Thorac Surg 2010;89(3):758-67; discussion 67 doi:

10.1016/j.athoracsur.2009.12.033[published Online First: Epub Date]|.

10. Abdel-Wahab M, Mostafa AE, Geist V, et al. Comparison of outcomes in patients having isolated transcatheter aortic valve implantation versus combined with preprocedural percutaneous coronary intervention. Am J Cardiol 2012;109(4):581-6 doi: 10.1016/j.amjcard.2011.09.053[published Online First: Epub Date]|. 
11. Gautier M, Pepin M, Himbert D, et al. Impact of coronary artery disease on indications for transcatheter aortic valve implantation and on procedural outcomes.

Eurolntervention 2011;7(5):549-55 doi: 10.4244/EIJV7I5A90[published Online First: Epub Date]|.

12. Ussia GP, Barbanti M, Colombo A, et al. Impact of coronary artery disease in elderly patients undergoing transcatheter aortic valve implantation: insight from the Italian CoreValve Registry. Int J Cardiol 2013;167(3):943-50 doi:

10.1016/j.ijcard.2012.03.089[published Online First: Epub Date]|.

13. Masson JB, Lee $\mathrm{M}$, Boone $\mathrm{RH}$, et al. Impact of coronary artery disease on outcomes after transcatheter aortic valve implantation. Catheter Cardiovasc Interv 2010;76(2):16573 doi: 10.1002/ccd.22501[published Online First: Epub Date]|.

14. Van Mieghem NM, van der Boon RM, Faqiri E, et al. Complete revascularization is not a prerequisite for success in current transcatheter aortic valve implantation practice. JACC Cardiovasc Interv 2013;6(8):867-75 doi: 10.1016/j.jcin.2013.04.015[published Online First: Epub Date]|.

15. Leon $M B$, Smith $C R$, Mack $M$, et al. Transcatheter aortic-valve implantation for aortic stenosis in patients who cannot undergo surgery. N Engl J Med 2010;363(17):1597607 doi: 10.1056/NEJMoa1008232[published Online First: Epub Date]|.

16. Smith CR, Leon MB, Mack MJ, et al. Transcatheter versus surgical aortic-valve replacement in high-risk patients. N Engl J Med 2011;364(23):2187-98 doi: 10.1056/NEJMoa1103510[published Online First: Epub Date]|.

17. Stortecky S, Buellesfeld L, Wenaweser P, Windecker S. Transcatheter aortic valve implantation: the procedure. Heart 2012;98 Suppl 4:iv44-51 doi: 10.1136/heartjnl2012-302401[published Online First: Epub Date]|.

18. Authors/Task Force m, Windecker S, Kolh P, et al. 2014 ESC/EACTS Guidelines on myocardial revascularization: The Task Force on Myocardial Revascularization of the European Society of Cardiology (ESC) and the European Association for CardioThoracic Surgery (EACTS)Developed with the special contribution of the European Association of Percutaneous Cardiovascular Interventions (EAPCI). Eur Heart J 2014;35(37):2541-619 doi: 10.1093/eurheartj/ehu278[published Online First: Epub Date]|.

19. Duncan A, Ludman P, Banya W, et al. Long-term outcomes after transcatheter aortic valve replacement in high-risk patients with severe aortic stenosis: the U.K. Transcatheter Aortic Valve Implantation Registry. JACC Cardiovasc Interv 2015;8(5):645-53 doi: 10.1016/j.jcin.2015.01.009[published Online First: Epub Date]|. 
20. Buellesfeld L, Gerckens U, Erbel R, et al. Age-stratified baseline and outcome characteristics of patients undergoing transcatheter aortic valve implantation: results from the German multicenter registry. J Invasive Cardiol 2012;24(10):531-6

21. Yamamoto $M$, Meguro K, Mouillet G, et al. Comparison of effectiveness and safety of transcatheter aortic valve implantation in patients aged $>/=90$ years versus $<90$ years. Am J Cardiol 2012;110(8):1156-63 doi: 10.1016/j.amjcard.2012.05.058[published Online First: Epub Date]|.

22. Sherif MA, Zahn R, Gerckens U, et al. Effect of gender differences on 1-year mortality after transcatheter aortic valve implantation for severe aortic stenosis: results from a multicenter real-world registry. Clin Res Cardiol 2014;103(8):613-20 doi: 10.1007/s00392-014-0690-6[published Online First: Epub Date]|.

23. Erez A, Segev A, Medvedofsky D, et al. Factors affecting survival in men versus women following transcatheter aortic valve implantation. Am J Cardiol 2014;113(4):701-5 doi: 10.1016/j.amjcard.2013.10.047[published Online First: Epub Date]|.

24. Zahn R, Gerckens U, Linke A, et al. Predictors of one-year mortality after transcatheter aortic valve implantation for severe symptomatic aortic stenosis. Am J Cardiol 2013;112(2):272-9 doi: 10.1016/j.amjcard.2013.03.024[published Online First: Epub Date]|.

25. Hayashida K, Morice MC, Chevalier B, et al. Sex-related differences in clinical presentation and outcome of transcatheter aortic valve implantation for severe aortic stenosis. J Am Coll Cardiol 2012;59(6):566-71 doi: 10.1016/j.jacc.2011.10.877[published Online First: Epub Date]|.

26. Kodali S, Williams MR, Doshi D, et al. Sex-Specific Differences at Presentation and Outcomes Among Patients Undergoing Transcatheter Aortic Valve Replacement: A Cohort Study. Ann Intern Med 2016;164(6):377-84 doi: 10.7326/M15-0121[published Online First: Epub Date]|.

27. Fusini L, Mirea O, Tamborini G, et al. Incidence and severity of atherosclerotic cardiovascular artery disease in patients undergoing TAVI. Int J Cardiovasc Imaging 2015 doi: 10.1007/s10554-015-0651-9[published Online First: Epub Date] |.

28. Freixa X, Chan J, Bonan R, et al. Impact of coronary artery disease on left ventricular ejection fraction recovery following transcatheter aortic valve implantation. Catheter Cardiovasc Interv 2015;85(3):450-8 doi: 10.1002/ccd.25632[published Online First: Epub Date]|.

29. Snow TM, Ludman P, Banya W, et al. Management of concomitant coronary artery disease in patients undergoing transcatheter aortic valve implantation: the United Kingdom TAVI Registry. Int J Cardiol 2015;199:253-60 doi: 10.1016/j.ijcard.2015.06.166[published Online First: Epub Date]|. 
Published in final edited form as: Int J Cardiol. 2017 Sep 15;243:150-155. doi: 10.1016/j.ijcard.2017.05.071.

30. Leon MB, Smith CR, Mack MJ, et al. Transcatheter or Surgical Aortic-Valve Replacement in Intermediate-Risk Patients. N Engl J Med 2016;374(17):1609-20 doi:

10.1056/NEJMoa1514616[published Online First: Epub Date]|. 


\section{FIGURE LEGENDS}

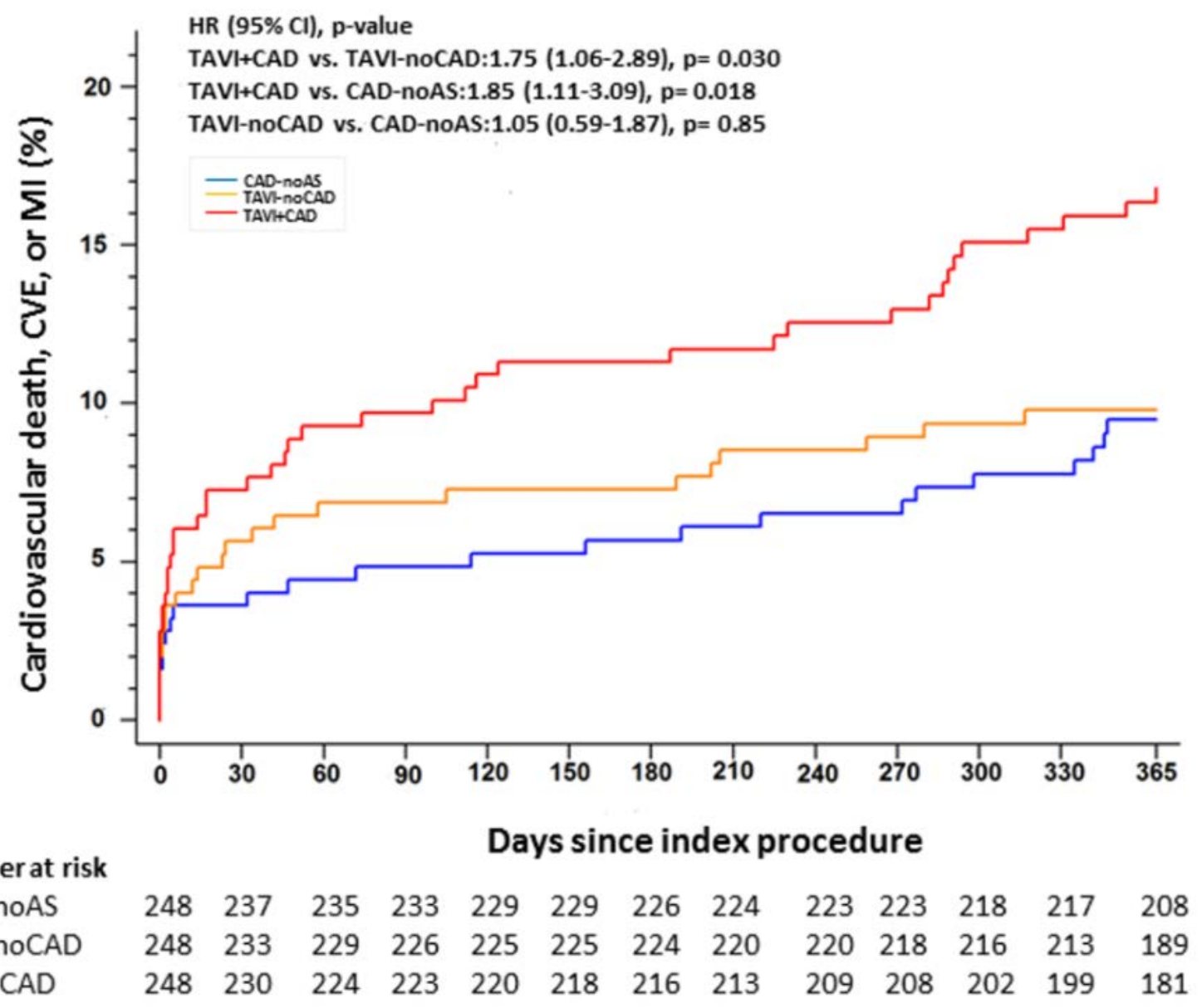

Figure 1- Cumulative incidence of adverse cardiovascular outcomes (composite of cardiovascular death, CVE, or MI) through one year in the three study cohorts - TAVI+CAD (red), TAVI-noCAD (orange) and CAD-noAS (blue).

AS: Aortic stenosis; CAD: Coronary artery disease; CVE: Cerebrovascular events; MI: Myocardial infarction; PCI: Percutaneous coronary intervention; TAVI: Transcatheter aortic valve implantation. 


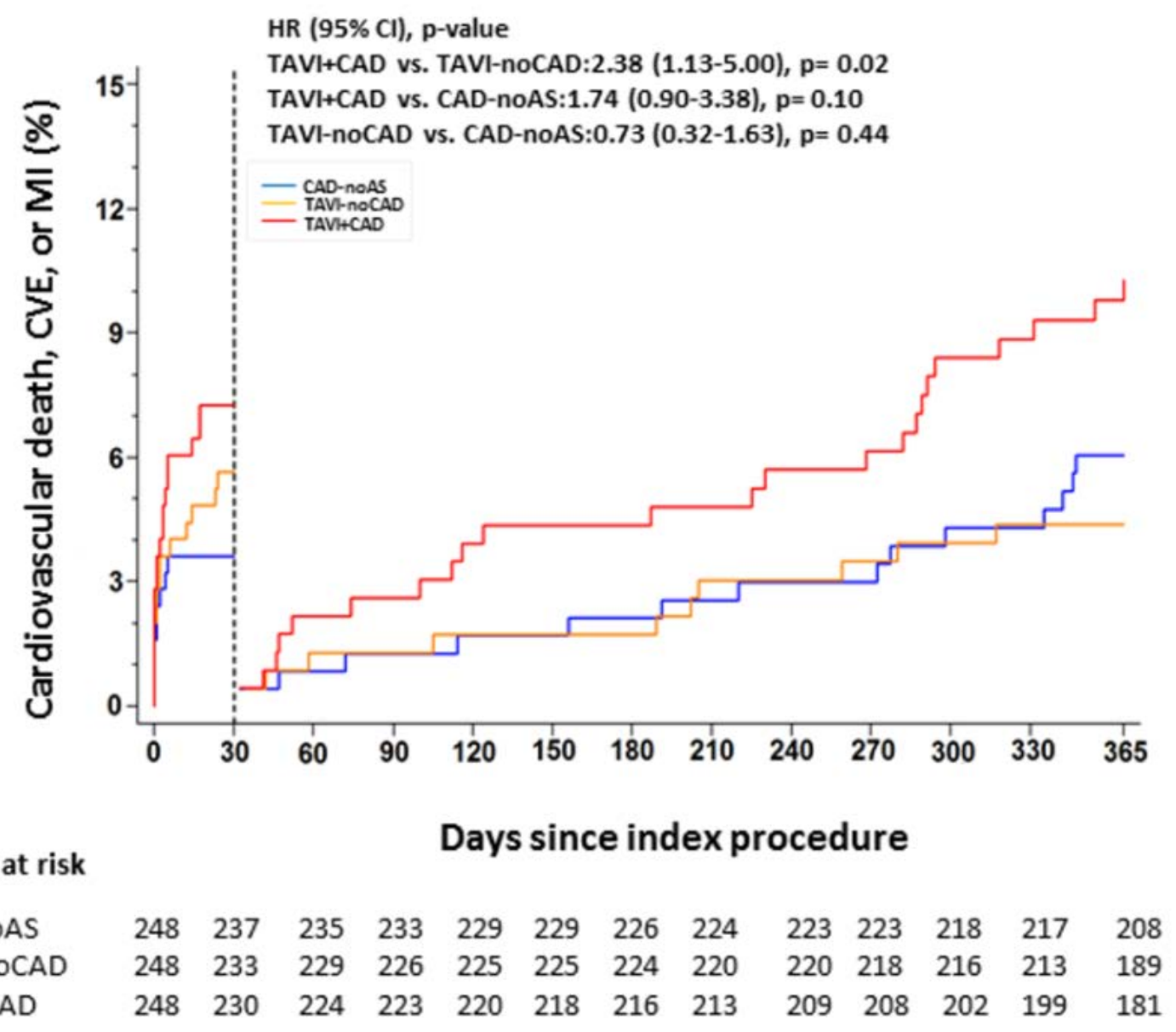

Figure 2 Cumulative incidence of MACCE (composite of cardiovascular death, CVE, or MI) during the first 30 days after procedure and thereafter for patients in the TAVI+CAD (red), TAVI-noCAD (orange) and the CAD-noAS cohort (blue).

AS: Aortic stenosis; CAD: Coronary artery disease; CVE: Cerebrovascular events; MI: Myocardial infarction; PCl: Percutaneous coronary intervention; TAVI: Transcatheter aortic valve implantation. 
Table 1. Baseline clinical characteristics

\begin{tabular}{|c|c|c|c|c|c|c|}
\hline & $\begin{array}{c}\text { TAVI+CAD } \\
\mathrm{n}=\mathbf{2 4 8} \\
\end{array}$ & $\begin{array}{c}\text { TAVI-noCAD } \\
\mathrm{n}=\mathbf{2 4 8} \\
\end{array}$ & $\begin{array}{c}\text { CAD-noAS } \\
n=248\end{array}$ & $\begin{array}{c}\begin{array}{c}\text { TAVI+CAD } \\
\text { vs. TAVI-noCAD }\end{array} \\
\text { p-value }\end{array}$ & $\begin{array}{c}\text { TAVI+CAD } \\
\frac{\text { vs.CAD-noAS }}{p \text {-value }}\end{array}$ & $\begin{array}{l}\text { TAVI-noCAD } \\
\frac{\text { vs. CAD-noAS }}{\text { p-value }}\end{array}$ \\
\hline Age (years) & $82.1 \pm 5.6$ & $81.9 \pm 5.7$ & $81.9 \pm 5.6$ & 0.72 & 0.62 & 0.89 \\
\hline Female gender, $n(\%)$ & $154(62.1 \%)$ & $154(62.1 \%)$ & $154(62.1 \%)$ & 1.00 & 1.00 & 1.00 \\
\hline Body mass index $\left(\mathrm{kg} / \mathrm{m}^{2}\right)$ & $26.1 \pm 4.7$ & $26.3 \pm 5.4$ & $26.7 \pm 4.7$ & 0.73 & 0.22 & 0.42 \\
\hline Diabetes mellitus, $\mathrm{n}(\%)$ & 83 (33.5\%) & $60(24.2 \%)$ & $46(18.5 \%)$ & 0.029 & $<0.001$ & 0.15 \\
\hline Insulin treated, $\mathrm{n}(\%)$ & $33(13.3 \%)$ & $22(8.9 \%)$ & $14(5.6 \%)$ & 0.15 & 0.005 & 0.22 \\
\hline Hypercholesterolemia, n(\%) & $190(76.6 \%)$ & $111(44.8 \%)$ & $163(65.7 \%)$ & $<0.001$ & 0.010 & $<0.001$ \\
\hline Hypertension, n(\%) & $222(89.5 \%)$ & $193(77.8 \%)$ & $209(84.3 \%)$ & 0.001 & 0.11 & 0.08 \\
\hline Peripheral artery disease, $\mathrm{n}(\%)$ & 49 (19.8\%) & $25(10.1 \%)$ & $28(11.3 \%)$ & 0.004 & 0.013 & 0.77 \\
\hline Previous CVE, $\mathrm{n}(\%)$ & $26(10.5 \%)$ & $18(7.3 \%)$ & $24(9.7 \%)$ & 0.27 & 0.88 & 0.42 \\
\hline Renal failure $\left(\right.$ GFR<60ml/min $\left./ 1.73 \mathrm{~m}^{2}\right)$ & $188(76.1 \%)$ & $168(67.7 \%)$ & $145(63.0 \%)$ & 0.045 & 0.002 & 0.29 \\
\hline Atrial fibrillation, $\mathrm{n}(\%)$ & $69(34.2 \%)$ & $66(32.2 \%)$ & $25(23.8 \%)$ & 0.75 & 0.068 & 0.14 \\
\hline Previous $\mathrm{MI}, \mathrm{n}(\%)$ & $56(22.6 \%)$ & - & $50(20.2 \%)$ & & 0.58 & \\
\hline Previous CABG, $n(\%)$ & $30(13.6 \%)$ & - & $23(9.3 \%)$ & & 0.15 & \\
\hline Previous $\mathrm{PCl}, \mathrm{n}(\%)$ & $90(36.3 \%)$ & - & $78(31.5 \%)$ & & 0.30 & \\
\hline Left ventricular ejection fraction(\%) & $54.0 \pm 15.4$ & $55.5 \pm 15.2$ & $56.2 \pm 14.1$ & 0.31 & 0.12 & 0.59 \\
\hline \multicolumn{7}{|l|}{ Medication at discharge } \\
\hline Aspirin, $n(\%)$ & $213(88.4 \%)$ & $200(81.6 \%)$ & $237(96.7 \%)$ & 0.042 & $<0.001$ & $<0.001$ \\
\hline Clopidogrel, $n(\%)$ & $181(75.1 \%)$ & $167(68.2 \%)$ & $213(86.9 \%)$ & 0.11 & 0.001 & $<0.001$ \\
\hline Beta-blockers, n(\%) & $122(65.2 \%)$ & $121(59.3 \%)$ & $157(64.1 \%)$ & 0.25 & 0.84 & 0.32 \\
\hline ACE inhibitors or ATII antagonists, $n(\%)$ & $133(71.1 \%)$ & 145 (71.1\%) & $179(73.1 \%)$ & 1.00 & 0.67 & 0.67 \\
\hline Statins, $n(\%)$ & $133(71.1 \%)$ & $77(37.7 \%)$ & $198(80.8 \%)$ & $<0.001$ & 0.022 & $<0.001$ \\
\hline Oral anticoagulants, $n(\%)$ & $68(28.2 \%)$ & $82(33.5 \%)$ & $38(15.5 \%)$ & 0.24 & 0.001 & $<0.001$ \\
\hline
\end{tabular}

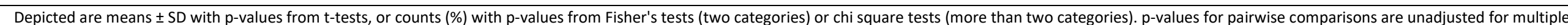

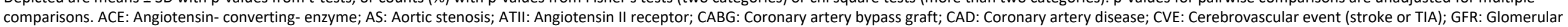
filtration rate; MI: Myocardial infarction; PCI: Percutaneous coronary intervention; TAVI: Transcatheter aortic valve implantation. 
Table 2. Clinical outcomes at 30-day and 1 year of follow-up

\begin{tabular}{|c|c|c|c|c|c|c|c|c|c|}
\hline & $\begin{array}{c}\text { TAVI+CAD } \\
n=248\end{array}$ & $\begin{array}{l}\text { TAVI- } \\
\text { noCAD } \\
n=248\end{array}$ & $\begin{array}{c}\text { CAD- } \\
\text { noAS } \\
n=248\end{array}$ & HR $(95 \% \mathrm{Cl})$ & $\begin{array}{c}\mathrm{p}- \\
\text { value }\end{array}$ & $\mathrm{HR}(95 \% \mathrm{Cl})$ & $\begin{array}{c}p- \\
\text { value }\end{array}$ & HR $(95 \% \mathrm{Cl})$ & $\begin{array}{c}p- \\
\text { value }\end{array}$ \\
\hline \multicolumn{10}{|l|}{ 30-Day follow-up } \\
\hline All cause death, $\mathrm{n}(\%)$ & $11(4.4)$ & $10(4.0)$ & $7(2.8)$ & $1.12(0.47-2.63)$ & 0.80 & $1.58(0.61-4.08)$ & 0.34 & $1.42(0.54-3.74)$ & 0.48 \\
\hline Cerebrovascular events, n(\%) & $8(3.2)$ & $11(4.4)$ & $0(0.0)$ & $0.73(0.29-1.82)$ & 0.50 & $\begin{array}{l}17.00(0.99- \\
292.94)^{*}\end{array}$ & 0.007 & $\begin{array}{l}23.00(1.36- \\
388.17)^{*}\end{array}$ & 0.007 \\
\hline Myocardial infarction, n(\%) & $1(0.4)$ & $0(0.0)$ & $6(2.4)$ & $\begin{array}{l}3.00(0.12- \\
73.29)\end{array}$ & 1.000 & $0.17(0.02-1.38)$ & 0.096 & $0.08(0.00-1.41)$ & 0.12 \\
\hline $\begin{array}{l}\text { Cardiovascular death, CVE, or } \\
\mathrm{MI}, \mathrm{n}(\%)\end{array}$ & $18(7.3)$ & $14(5.6)$ & $9(3.6)$ & $1.30(0.64-2.61)$ & 0.47 & $2.02(0.91-4.50)$ & 0.085 & $1.56(0.68-3.61)$ & 0.30 \\
\hline \multicolumn{10}{|l|}{ 1-year follow-up } \\
\hline Myocardial infarction, n(\%) & $5(2.2)$ & $0(0.0)$ & $10(4.1)$ & $\begin{array}{c}11.00(0.61- \\
197.87)\end{array}$ & 0.061 & $0.51(0.17-1.48)$ & 0.22 & $0.05(0.00-0.85)$ & 0.30 \\
\hline $\begin{array}{l}\text { Cardiovascular death, CVE, or } \\
\mathrm{MI}, \mathrm{n}(\%)\end{array}$ & $41(16.8)$ & $24(9.8)$ & $23(9.5)$ & $1.75(1.06-2.89)$ & 0.030 & 1.85 (1.11-3.09) & 0.018 & $1.05(0.59-1.87)$ & 0.86 \\
\hline
\end{tabular}

Depicted are counts (incidence rates \% from Kaplan Meier life-tables).

Hazard Ratios HR (95\% Cl) from Cox's Regressions. * Continuity corrected Risk ratios ( $95 \% \mathrm{Cl}$ ) with p-value from Fisher's test. AS: Aortic stenosis; CAD: Coronary artery disease; CVE: Cerebrovascular events; MI:

Myocardial infarction; PCl: Percutaneous coronary intervention; TAVI: Transcatheter aortic valve implantation. 